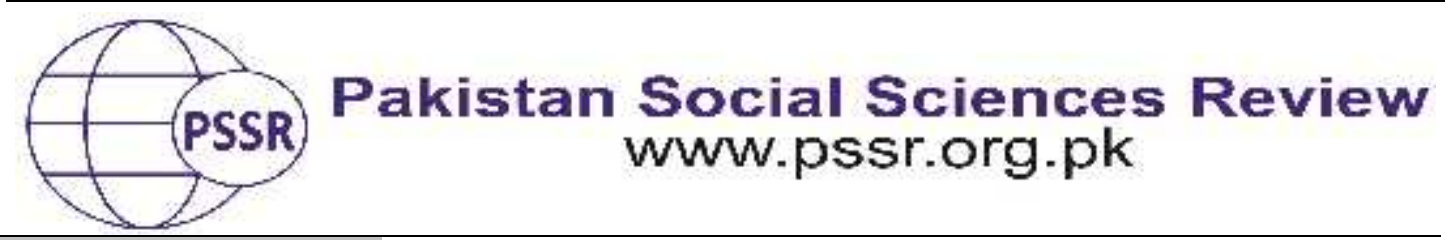

RESEARCH PAPER

\title{
Pedagogical Stylistics: Cognitive Stylistic Analysis of Simon's The Sound of Silence
}

\author{
Dr. Shaista Zeb* ${ }^{1}$ Dr. Rubina Masum ${ }^{2}$ Dr. Afsheen Salahuddin ${ }^{3}$
}

1. Assistant Professor, Department of English, National University of Modern Languages Islamabad, Lahore Campus, Punjab, Pakistan

2. Assistant Professor, Department of English/Business Management, IQRA University, Karachi, Sindh, Pakistan

3. Assistant Professor, Adjunct Faculty at School of Education, Beaconhouse National University, Lahore, Punjab, Pakistan

\begin{tabular}{|c|c|}
\hline PAPER INFO & ABSTRACT \\
\hline $\begin{array}{l}\text { Received: } \\
\text { March 23, } 2021 \\
\text { Accepted: } \\
\text { June 20, } 2021 \\
\text { Online: } \\
\text { June 25, } 2021\end{array}$ & $\begin{array}{l}\text { The study is concerned with the exploration of cognitive } \\
\text { stylistic in the Simon's The sound of silence in order to highlight } \\
\text { the deployment of different cognitive stylistic devices and use } \\
\text { of mental processes on the understanding of meaning. These } \\
\text { mental spaces help in establishing grammar that shows the }\end{array}$ \\
\hline $\begin{array}{l}\text { Keywords: } \\
\text { Cognitive, } \\
\text { Mental Space, } \\
\text { Stylistics, } \\
\text { Perspective }\end{array}$ & $\begin{array}{l}\text { perspective understanding but also used to represent dynamic } \\
\text { textual features, this study draws on Text World Theory (Werth, } \\
\text { 1999; Gavins, 2007), but also integrates some aspects of }\end{array}$ \\
\hline $\begin{array}{l}\text { *Corresponding } \\
\text { Author }\end{array}$ & $\begin{array}{l}\text { Cognitive Grammar (Langacker, 2008). The article pays } \\
\text { particular attention to the way Gaiman frames his narrative and } \\
\text { positions his reader to view the fictional events from a } \\
\text { distinctive vantage point and how such writing is designed } \\
\text { with a particular readership in mind. }\end{array}$ \\
\hline
\end{tabular}

\section{Introduction}

Cognitive stylistics goes beyond stylistic for literary explanation by linguistic models to explore the parallel and the peculiarity in reading experiences based on cognitive scientific perception into the relation between the mind, language and the world. One challenge for cognitive stylistics researchers in contemporary stylistics is to describe how readers interpret literary texts by showing the difference and assist it between their own world and the author's world. Werth (1999) seeks to explain the conceptual space that connects the different worlds of communication to the author and reader levels of interpretation of the text. This process makes an important new style of interpreting, conceiving the writing and reading process. 
Paul Simon, born in 1941, is an American musician, singer and songwriter. His fame began as being part of the duo Simon \& Garfunkel that was formed in 1964 with the musical partner Art Garfunkel. "The Sound of Silence" is one of his most popular songs with a high chart performance played in the 1960s by the famous duo Simon and Garfunkel.

The survival of our world is mannered by time and space. As Merleau - Pony (1962) states, we live always in the factual environment, at a specific present location. Thus at any case of time we are 'grounded' on what is called our physical existence and perspective which is taken on our personal experience of the world around us is govern by the particular facts of the domain that includes the social-cultural knowledge, norms and personal experience, the memories people have, and so on (the ideal cultural cognitive model). As humans, however, it is the ability to go beyond the limits of that reality space by come up with of other conscious 'mental spaces'. These cognitive conditions can change time (past or future) and space (other locations) as well as creating other kinds of proportions such as hypothetical or false spaces. Fauconnier(1994) Has shown how these mental spaces can be constructed vigorous in the way that shows how humans can think, perceive, interpret and reason. Fauconnier\& Turner (2002) have polished the theory further to show how humans are able to create new thoughts from these spaces in addition to already ' blended' spaces (Simpson,2004).

The study investigates the main types of cognitive stylistics is marked and how reader's mind is restored by different mental representations, perceptions and conceptualizations. It tries to recognize the essential work of cognitive stylistics in the selected lyrics. It is assumed that cognitive stylistics which means the link between linguistics, literary studies and cognitive science is used as an influential tool to survey text processing and interpretation of the literary or linguistic text. The steps followed in this study are surveying cognitive stylistics, identifying its main mental contraction and showing how cognitive stylistics can influence the rules of grammar especially the rules of self-anaphor and deixis. Furthermore, to explain how the writer self-anaphors are activated and grounded in cognitive spaces, and that their use signals a projection from one mental space into another.It is hoped that this study will provide a help for students of literary and linguistic studies in understanding the main tools of cognitive stylistics showing the main role played by them in meaning construction of the literary text. Also, study presents not only new explanation of a particular text but also important perception into the reading process. This study concludes that the employment of figures of speech is pervasive and prominent in The Sound of Silence which produces a coherent and solid text featured by creativity and novelty.

\section{Literature Review}

Stylistic analysis tends to build linguistic theories or frameworks in order to explain or predict the point of view of the writer and reader. The new about cognitive stylistic is the way in which linguistic analysis is organized based on theories that relate linguistic devices to cognitive structures and processes involved 
in the formation of the text. This provides more systematic and direct accounts of the relationship between texts on one hand and responses of that text and interpretation, understanding on the other.

What makes cognitive stylistics somewhat different is its relationship to cognitive science. It is meant that cognitive theory of linguistic and the cognitive psychology of reading are two fields that are connected directly to cognitive stylistics. Reading procedure and cognition have become the useful approach of exploration for those in stylistics. By including the human mind, cognitive stylistics opens up a new field for literary study and literary analysis. That is to pay consideration to the mind when conducting a stylistic analysis of cognition.Some of the important points and devices are used to transfer, modify, interpretation and blend mental construct are schema theory, text world theory, conceptual metaphor and mental space theory which play a vital and important role in cognitive stylistics.

Pragmatics and stylistics directly connect with the effect of reading and meaning on the reader. Cook (1994, p. 10) points out that "schemata are essential to text processing, but can be both a potential barrier to understanding or enable a greater understanding of a text". He argues that certain uses of language can change our representation of the world and literary language and literature by its very nature is schema altering or schema renewing or schema reinforcing relative to reader expectation, interpretation or knowledge of the literary text.

Cook (1994) points out that while some writers (Van Djik and Kintsch, 1983) regard cohesion as an instance of coherence and others (Brown and Yule 1983) consider the two as different in linguistic terms. Coherence is the result of an interconnection between text and reader.

Wreth (1997) and Gavins (2001) state that metaphor forms a type of epistemic sub world in the text world. According to Lacoff and Tumer (1989) and Lackoff and Johnson (1980) metaphors are ontological and epistemic mapping across conceptual domains, that is, from source domain to target domain.Porto Ruekijo (2007) points out that metaphors play a very important role in text worlds because in actuality, text world can be sensed through knowledge of the real world. In schema theory, metaphors create new ways of mapping the real world on the textual world, therefore they extend or alter the schemata. Mostly, metaphors are conventional, culture specific and understood within a community of speakers. As Ruekijo (2007) states that creation metaphors in a text can produce significant, even if transitory changes on the way the world is perceived.

Mental spaces are models of discourse understanding; they are interconnected with it and can be modified to the extent of its deployment as fragments, pieces of text world. Mental spaces are based on the access principle of one mental space through another and they are constructed for understanding counterfactual statements, artifacts or local context of discourse. In the theory of mental spaces, a real basic space of mental representation of all the perception is 
built. They are constructed by certain elements , such as: 1) space builders that take on variety of grammatical forms, such as prepositional phrases, adverbials and introductory words, conditional sentences (if, even) and subject predicate complexes( she thinks, believes..).Their function is to represent the existing mental space or enter a new one; 2) the roles and their values - they are the main parts of mental spaces, 3) trans, spatial operators-they are elements that connect spaces represented by copulative verbs such as be , became, remain; and 4) connectors that link the objects ( roles) spaces. Connectors allow making references to one of these objects in terms of the other according to the principle of identification or access principle (Fauconnier, 1994; Fauconnier, 1997).

\section{Material and Methods}

This study focuses to investigate the utility of using poetry in language teaching classroom and explored whether inclusion of poetry in language teaching enhance language development of learners. Questions were asked to gauge the understanding of the concept and author-reader relation was determined. Participants answered the questions and their responses were described. This study was conducted by engaging undergraduate students from NUML, Lahore (session 2017-2021) as population of the study. The students utilized literature-based activities to develop their linguistic competence. Text based activities is a new approach which encourages using fiction and poetry in English language classroom. This method can easily be applied in classroom as this is known as low technology approach. Words and their appropriate usage of literary text is the key point on a page to be talked about and interpreted. In this paper, the literary text is used for explaining and understanding, as well as stimulating readers for practicing the language skills. This text is utilized to generate literature based activities analyzed for its use in English language classroom. The analysis is emphasized on the linguistic inputs that readers/students receive.

Text World Theory is selected as a discourse framework for the macro analysis of the selected poem. Then, Blending Theory is used for a detailed analysis of sentence-level metaphors in the text. These analyses reveal that each of the theories tackles particular aspects of the literary text and their combination can lead to a fruitful strategy that introduces a holistic investigation of the selected poem and exposes its complexities and intricacies. Therefore, both approaches are integrated in the analysis. This integration proves to be useful in developing an effective analytical tool that enables readers to fully understand the narrative and uncover the hidden messages and concealed realities of the world to readerships.

\section{Results and Discussion}

Although "The Sound of Silence" was composed almost 55 years in the past, its gloomy and mysterious concepts are extraordinarily noteworthy as well as pertinent at present circumstances. Simon's verse exhibits an intense private emotion and engages basically with an unusual individual practice. It is far inculcated by the angle of an orator who believes that he has a vital thought to convey towards human 
beings ingrained in philistinism, an individual who fantasize more ethical and willful surroundings. The verse provides a bitter depiction of a humanity enclosed in philistinism and selfishness. An individual's uneven behaviors are truthful depiction of present lifestyles which may lead to loss of significant interactions in our presentday capital environment. Present lifestyles, as Simon portrayed it, increase the experience of isolation, solitude and dislodgment.

The destiny of human kind appears ominous. Individuals appear tremendously ingrained within fabric lifestyles without considering worth of their existence as human beings, and precisely the pair said in their most primitive video version capability to engage with individuals, sensitively in order to observe persons in surroundings incapable to care for each other which is stated as sound of silence".

Within The sound of Silence, Simon utilizes numerous literary devices: consisting of simile, metaphor, personification, paradox, apostrophe, etc. The following abstract gadgets turn to be significant components during deciphering and interpreting other meanings of lyrics. The accompanying part is apprehensive about giving more subtleties on the utilization of metaphors as highlights of inventiveness and peculiarity in this verse.

\section{Design of Innovativeness and Oddity in The Sound of Silence}

The following segment centers around three different examples of speech assortments that Simon firmly infers within verse to depict latest figurative and calculated picture compositions highlighted by curiosity and innovativeness to be used in speech.

\section{The Logic between Figures of Speech}

\section{Apostrophe}

Due to logic in practice and information, Simon decides intelligibility in between metaphors to make fresh elaborative systems known as innovativeness and oddity. As example, exactly inside the verse, "Hello darkness, my old friend", Simon utilizes punctuation, that is a significant metaphor, particularly inside the poem. Apostrophe is "practically one and same with the verse tone" (Kennedy \&WershlerHenry 2006). It is for the most part wanted to address missing individuals or represented things. At the end of the day, Apostrophe as a metaphor is related, within its utilization, by means of exemplification. Within "The Sound of Silence", Simon utilizes Apostrophe to manage represented "obscurity" by utilizing "hi", which might be a welcome word which will be wont to welcome an individual that one witnesses or gets together with. "Obscurity" is in this way depicted here as a cozy individual who the storyteller want to see and meet. Henceforth, the figurative recipe which will be caught by semantic development "Hello darkness "is that darkness might be an individual. 


\section{Personification}

Personification, alternatively, is developed by providing "obscurity" some individual qualities through characterizing some terms interrelated to persons (hello, friend, talk, and you). As Lakoff \& Turner (1989) reveal, Personification allows individuals to utilize facts concerning ourselves to utmost outcomes, utilize wisdom concerning ourselves to aid us figure out terms as forces of environment, ordinary happenings, nonfigurative ideas, and lifeless matters".

Simon really hoists idea of dimness to degree of an individual's character. this is frequently without a doubt one among the representation's certain highlights to make the story intriguing and clear, and it possibly progressively recognizable in the beautiful piece where peruses comprehend things as populace.

Surely, when an individual's life form acquires "gloominess " as one's "companion", he cannot envision to what extent he observes forlorn. Subsequently, tending to "darkness" as his companion passes on very one significance: from one perspective, there is no one to talk with, or rather no one might truly want to focus to him. It is consequently a sign to the holes among people groups likewise on his own depression as well.

\section{Paradox}

Paradox might be an overstatement which is utilized to hitch words or enunciations by each other with opposite energies. In "hello darkness, my old friend" (verse 1), Simon interprets "companion" that is a private individual inside the source space to "darkness" which might be a $\mathrm{n}$ inert remarkable thought inside the goal region. Through this mapping, "darkness" changes into an agreeable individual who can tune and tune in to what the storyteller should portray. Be that since it might, as demonstrated by our scholarly getting, "darkness" might be a dead and unfriendly thing, so by what means can an unfriendly thing be a friend. It's totally the force of intriguing articulations, by means of which Simon joins two reverse plans to shape another allegorical formula which will be stirred up here as darkness might be a Partner. This depiction is practiced by applying Catch 22. Thusly, to get a handle on the image graphs and thusly the association that Simon develops between "darkness" and "friend", pursuers got the chance to apply a technique of psychological depiction considering the very certainty that symbolic conceptualization might be a technique of plotting among two various determined spaces Glucksberg \& McGlone (2001).

As of interest and creative mind perception in linguistics, "hello darkness, my old friend. I've come to talk with you again" (line1-2), might be an unbelievable allegorical picture, by way of which Simon makes new explanations that irrefutably pass on novel ramifications by using the worldview of adequacy with intriguing articulations. In particular, the portrayal of "darkness" is shaped and spoken to in three synchronous and sensible intriguing articulations to stress it because of the prevalent quietness. Also, the utilization of accentuation, representation and 
peculiarity in one line and during a sensible progression makes meanings obvious and correct. This wonder, as Lakoff \& Turner (1989) put it, is a noteworthy component of untainted works, since something that depicts great deliberation that is the concurrent practice of at least two such figures during a comparative segment, or possibly during a comparative sentence. As showed by Leech (1969), an author is nobody if not innovative, and as language is his forum, he attempts to shape new useful possible results which aren't starting at now inside the speech. Simon, as an author, demonstrates a clear-cut limit of controlling words and amassing three interpretive contraptions collectively to draw an obvious and charming symbolic picture included by interest.

In verse four "(line 2), Simon uses representation to accept "Silence like a cancer grows" "to "dangerous development". It's possibly significant here to remind ourselves that the utilization of analogy isn't self-self-assured at all as "the choice of the relationship notices to us what features to move and the best approach to understand the objective space" (Foley 2009). Thusly, to depict "silence" as "cancer" is to call attention to an overstated representation of the results as though "silence" rules during a culture, even as to state to what degree quietness is perilous.

This is another applied mapping among the source territory "dangers" besides, the objective space "quietness" which gives a significantly pessimistic appraisal of "quietness". It's a discouraging and a critical infection that creates bit by bit to direction over the community forcing it in the end to mortality as danger does to an individual's body. People need thusly to contradict and empty calm from an overall population as their call for considering and clearing harmful development from an individual's body. Because of this mapping, the new allegorical condition which will be gotten here is that "SILENCE IS PASSING". People have accordingly to count on their genuine encounters and knowledge about harm to consider another mapping even as to appreciate the idea that the craftsman expects to convey here.

\section{Extended and Advanced Non-Exacting Verbalizations}

As inventiveness is far of the time normal inside the structure of the comprehensive and complex non-strict explanations, stanza is that the finest space to make such verbalizations because the ideal schemes use the instrument of normal notion, yet it expands, clarifies and unites them in habits that go past the normal.

In stanza four, "but my words, like silent raindrops fell" (line 5) Simon makes another non-strict framework where words are appeared differently in relation to raindrops. This allegorical structure arrives at call at the going with lines (6-7) "and resonated", "in the wells of silence" to conceal other non-literal enunciations. Therefore, we find a gathering of allegorical pictures which are collected simultaneously to shape one extended metaphorical structure that infers plainly how the storyteller talks, anyway his words turn into a touch of the calm. Since, raindrops fell peacefully when there's nothing to fell on, and voice resonates when a place is 
vacant. In this way an image is shown that there's no one there to tune in to his words.

This can be seen as an emphasis or rather a certification of the hidden picture that Simon delineates inside the essential verse when the storyteller wants to talk to haziness since there's no one to banter with. The most single differentiation between the two pictures, is while the essential is an effect of the depiction inside the certified world, the contrary picture might be a bit of the storyteller's dream where he finds people, be that since it might, they lost their ability of tuning in and talking. The 2 pictures reflect and underline the dominance of quietness by and gigantic and each one over.

In the meantime, and snared in to the idea of interest by passing on the component of metaphorical mapping in theoretical works, researchers of composing reliably look to develop new sorts of relationship among target and source spaces. They are moreover amped up for expanding and elucidating in the wake of existing representations in a few ways.

For instance, in verse two, "When my eyes were stabbed by the flash of a neon light" (line 5) an additional indication of another widely inclusive non-strict agenda that proposes a new vision in "The Sound of Silence". The craftsman makes another non-literal picture during which "neon light", or "neon god" as he names it inside the last verse, is encapsulated as a colossal and a mighty individual, with its "flash", which is represented as a strong arm; it cuts, parts and contacts. It's another symbolic structure made during a progression of exercises by rousing the source space by activity words and crediting them during a structure of exercises to the objective space. It is, clearly, the force of charming theory to make new composite starts from easy standard musings.

To put it diversely, as Simon unequivocally change our perspective on lack of clarity, he adjusts it again anyway unfavorably this point about the "neon light". However, "darkness" is depicted as an agreeable partner inside the chief line, "light" is represented as a compelling individual here. It's possibly fundamental to exact that innovativeness and peculiarity are also appeared by the contradicting sign of stuff during this stanza, through which Simon intended to show a reasonable picture of the authenticity that rules people's life.

\section{Conclusion}

This cognitive stylistic analysis illustrates some of the ways of using figures of speech varieties as features of creativity in language use. The Sound of Silence is rich with different forms of figures of speech that Simon employs, in a professional way, to produce a coherent and solid text characterized by creativity and novelty. Simon successfully employs figures of speech to lead his readers to form a clear image from the fragmentary pictures that he presents in his lyric. He always chooses the appropriate literary device to communicate what he thinks and how he feels about something, to explain what a particular thing is like and to convey a meaning 
in a more interesting and creative way. It offers lots of new images schema, new conceptual metaphor and new types of mapping between source and target domains. Simon has achieved these techniques by (1) employing the strategy of coherence among figures of speech, (2) using new conceptual mapping and new stylistic frameworks, and (3) deploying some extended and complex figurative expressions that lead to create new figurative frameworks which illustrate the idea of novelty and creativity in the language used in this lyric. 


\section{References}

Anderson, R. (1984). Role of the reader's schema in comprehension, learning, and memory. In R. Anderson, J. Osborn, \& R. Tierney (Eds.), Learning to read in American schools: Basal readers and content texts, pp. 243-257. Hillsdale, NJ: Erlbaum.

Black, M. (1962). Models and Metaphors, Ithaca: Cornell university press

Breton, A. (1969). Manifestoes of Surrealism [translated by R. Seaver and H.R. Lane] Ann Arbor, MI: University of Michigan Press.

Brown. \&Yule, G. (1983). Discourse Analysis. Cambridge: Cambridge University press

Cook, G. (1994). Discourse and Literature. Oxford: Oxford University Press.

Fauconneir, G. (1997). Mappings in Thought and Language. Cambridge: Cambridge University Press.

Fauconnier, G. (1994). Mental Spaces: Aspects of Meaning Construction in Natural Language. Cambridge: Cambridge University Press.

Gavins, D. (2007). Text World Theory: An Introduction. Edinburgh: Edinburgh University Press.

Johnson, T. H. (ed) (1963). The Poems of Emily Dickinson, 3 vols. Cambridge, M.A: The Black nap Press of Harvard University Press.

Lackoff, G. \& Johnson, M. (1980). Metaphor s We live, University of Chicago Press.

Lackoff, M. \& Turner, M. (1989). More than Cool Reason: Afield Guide to Poetic Metaphor. Chicago: Chicago University Press.

McCauley, J. D. (1981). Everything that Linguists have always wanted to know about logic (But where Ashamed to Ask).Chicago, The University of Chicago Press.

Merleau. M. (1962). Phenomenology of Perception [ trans. C. Smith] London: Rutledge

Kegan Paul. Semino,E \& Culpeper, J. (eds) (2003). Cognitive Stylistics: Language and Cognitive in Text Analysis. Amsterdam: John Benjamin.

Simpson, P.(2004). Stylistics: A Resource Book for Students. London: Rutledge.

Sperber, D. (1986). Relevance: Communication and Cognition, Oxford: Blackwell.

Ungerer, F. \& Hans-JorG S. (2006). An Introduction to Cognitive Linguistics. London: Longman. 
Van Dijk, T.A (1983). Strategies of Discourse Comprehension. London: Academic Press.

Walsh, G. (2010). Schema Poetics and Crossover Fiction. In contemporary Stylistics ed. by Marine Lambrau and Peter Stockwell. London: Continuum

Weber, J.J. (1996). The Stylistics Reader. London: Edward Arnold.

Werth, P. (1999). Text Worlds: Representing Conceptual Space in Discourse. London: Longman. 


\section{Appendix-1}

The Sound of Silence

Hello darkness, my old friend

I've come to talk with you again

Because a vision softly creeping

Left its seeds while I was sleeping

And the vision that was planted in my brain

Still remains

Within the sound of silence

In restless dreams I walked alone

Narrow streets of cobblestone

'Neath the halo of a streetlamp

I turned my collar to the cold and damp

When my eyes were stabbed by the flash of a neon light

That split the night

And touched the sound of silence

And in the naked light I saw

Ten thousand people, maybe more

People talking without speaking

People hearing without listening

People writing songs that voices never share

No one dares

Disturb the sound of silence

“Fools," said I, "You do not know

Silence like a cancer grow 
Hear my words that I might teach you

Take my arms that I might reach you"

But my words like silent raindrops fell

And echoed in the wells of silence

And the people bowed and prayed

To the neon god they made

And the sign flashed out its warning

In the words that it was forming

And the sign said "The words of the prophets

Are written on subway walls and tenement halls

And whispered in the sounds of silence 